\title{
"The men make it seem like a secret society..." The struggle for control over 'direct inputting' of classified advertising in the New Zealand newspaper industry
}

\author{
Roberta Hill*
}

This paper draws on a detailed empirical study of the New Zealand newspaper industry undergoing technological transformation to illustrate why an analysis of the labour process which adopts the classic Marxist problematic, class-in-itself and class-for-itself, is limited. Instead the paper uses a 'relational' analysis (see Elbaum et al., 1979; Stark, 1980; Hill and Novitz, 1985) to show that answers to questions about control in the workplace must be sought by analysing gender as well as class relations, and the complex interaction between the two.

\section{Introduction}

This paper presents a case study, during the period between 1980 and 1983, of the struggle for control of the new technology involved in 'direct inputting' of telephone advertisements ('phone ads'). It documents relations of conflict and compromise that were forged among and between management and workers, and men and women in the New Zealand newspaper industry to try to gain or retain control over the new labour process. The paper draws on a rich source of qualitative data generated during 22 months of fieldwork in 10 different production departments at The Star in Christchurch, as well as from oral and written submissions to the Arbitration Court during hearings into a demarcation dispute between the New Zealand Printers' and Clerical Workers' Unions. This dispute occurred during the course of the fieldwork, and over the period of planning for the implementation of the new system of classified advertising, the Classified Management System (CMS system) (Hill, 1983; Hill and Gidlow, 1988).

Although the CMS system was introduced in March 1982, it had been technically feasible to implement the direct-inputting of telephoned ad copy two years earlier. The delay in introducing the system was the outcome of a process of struggle and negotiation between groups inside The Star, and in the New Zealand newspaper industry generally. Figure 1 illustrates, schematically, the relations of conflict and alliance among the key

* Social Science Unit, Department of Scientific and Industrial Research

This paper was originally presented at the second annual Labour History Conference, Auckland University, 24 September 1988. I am grateful for the significant contribution which Bob Gidlow has made towards editing this paper and for the technical support provided by Lynda Megson. 
groups. The struggle between these groups influenced the timing of the introduction of the system at The Star, the way in which the restructured jobs were allocated and the nature and level of skill which they entailed.

The first section of the paper familiarises readers who have little prior knowledge of the newspaper industry with the technologies involved so that they can appreciate the discussion which follows.

\section{Production changes at The Star - a background}

Following the major production change at The Star in 1979 and 1980 from hot metal to cold type technologies 1 , a second major change occurred early in 1982 , when a fully computerised system for processing classified advertising, the CMS system, was introduced. This system directly affected the work of 22 telephonist-typists who retrained - as 'tele-ad operators' - to record and typeset telephoned advertisements using a visua display terminal (VDT). The new system also significantly changed the work of 14 other clerical workers in the classified advertising department and the work of former linotype operators, compositors and proof-readers at The Star.

These two successive changes meant that The Star had produced columns of classified advertising by three different methods over a 5 year period. Firstly, until the change to cold-type production in May 1980, classified ad copy was produced in hot metal Secondly, from May 1980, to March 1982, typesetting and composition were computerised using a CM11 system. (Figure 2 shows the flow of work under this system.) However, the potential of the system was not fully exploited until March 1982 when the third method was introduced and the telephonist-typists began retraining under when the third method was introduced and the telephonist-typists began retraining under
the Classified Management System. With this system of direct-inputting, telephoned ads were keyed directly into the data base via VDTs. The ads were then phototypeset without any further keyboarding.

\section{The organisation of work before and after the change}

The three different methods of production can be understood by distinguishing between 'hard copy' (typed or written material) and electronic copy (displayed on the screen of a computer terminal)

Under both hot metal and the CM11 system all classified advertising originated as hard copy. This copy came from three main sources: ads received over the telephone by telephonists who used head-sets and typewriters to record the details on pre-printed forms; ads received from customers in written form through the mail or at the front counter of The Star's offices; and copy solicited from local businesses by sales staff. This hard copy was routed to the composing room where, under hot metal, linotype or teletypesetter (TTS) operators set the lines of type for composing in the metal pages; and under the CM11 system, VDT operators entered the copy into the computer using VDTs, and TTS operators produced punched tape which could be 'read' into the computer. In other words, the operators reproduced - in both hot metal and in cold type - the details of the ad from hard copy. Hence, for every ad that appeared in the newspaper, there was a corresponding piece of paper in typed or written form.

With the CMS system, telephonist-typists no longer produced hard copy versions of the ad, since the recording of the contents and its setting into type were carried out during

1 'Hot metal' is the term used in the printing trade to refer to the method of setting type by linotype or linecasting machines, where type images or slugs are cast from molten metal. The 'cold type', or computer-based, method of typsetting creates type as artwork on photographic paper in a photo-electronic process referred to as photocomposition.
Figure 1: Conflict (-----) and alliance (- ) among key groups over direct-inputting of telephone advertisements
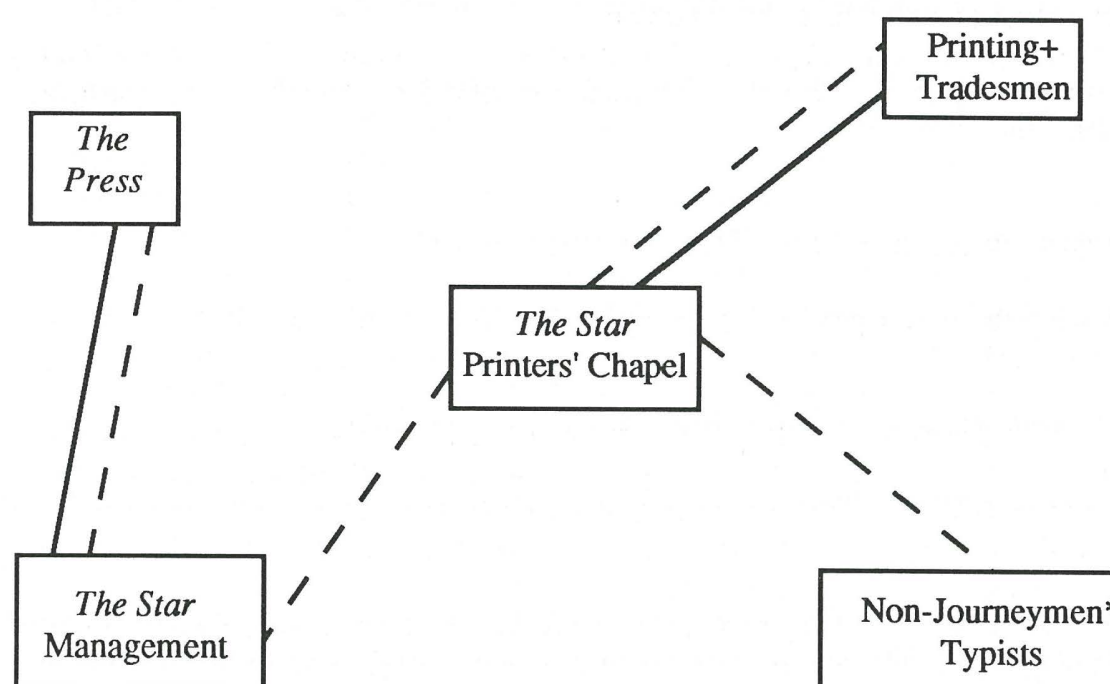

Management

Non-Journeymen* Typists

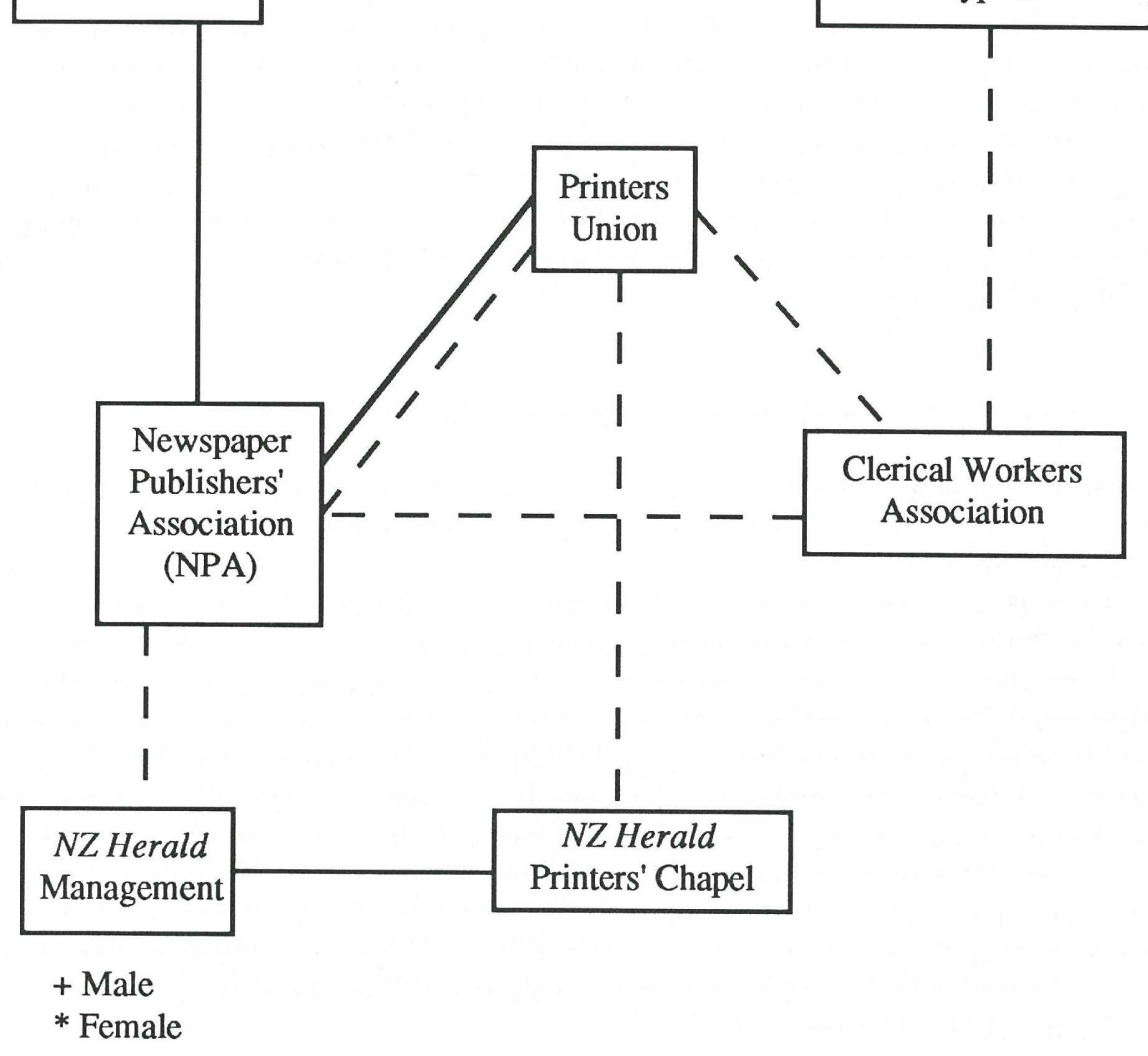




\section{Roberta Hill 270}

the one operation (see Figure 3). Instead of working with typewriters the women operated VDTs and as they keyed in the wording of the ad and billing details from the customer, they also entered the information into the computer's data base using computer commands.

Once the ads were entered, they could be manipulated in a number of ways. On the appropriate 'run date' the ads would be recalled from computer storage by a system controller (a retrained printer) and photoset in alphabetical order in columns of the correct classification. Since the telephoned advertisement was in electronic form during this in print' the initial keystrokes of the retrained the need for further keyboarding by printers in the composing room.

\section{Conflict and alliance within the newspaper industry}

Conflict and compromise between the Newspaper Publishers Association and the Printers Union

Direct inputting of telephoned ads ran counter to the interests of the Printers Union. Overseas experience showed that new technology reduced employment opportunities for printing tradesmen, with the consequence that union membership declined and the traditional control of the printers over typesetting was eroded. The New Zealand Printers Union's collective interests were best served if control over typesetting was retained. Therefore the union pursued a strategy to bring the telephonist-typists (who were clerical workers) into the union as 'non-journeymen' members.

For their part, newspaper employers were keen to see the extension of computerised technologies to advertising copy. Eliminating double keyboarding of telephoned ads was expected to reduce labour requirements since VDT and TTS operators no longer needed to typeset the ads from hard copy. In turn, reduced wage costs would keep advertising charges down, and the single handling of ads would reduce opportunities for error. Both these factors could be expected to enhance the appeal of newspaper advertising relative to other media.

However, newspaper employers wanted to avoid the confrontation with printers that had occurred overseas (see Hill, 1983, pp 96-97) and they had good reason to believe that the Printers Union would refuse to work with non-union members engaged in typesetting tasks traditionally done by printers. For example, in negotiations in the mid-seventies, employers sought the union's attitude to their proposals to install electronic equipment for direct-inputting of telephoned advertisements. Responding, the union had "welcomed the opportunity for increased advertising revenue for newspaper houses but maintained their traditional rights to typesetting". During 1977, employers, represented by the Newspaper Publishers' Association (NPA), accepted the view of industry assessors that since retrained telephonist-typists "were to be required to do a traditional printing function, i.e., the setting of type, provision had to be made in the award for these functions"2. As a result, Clause 35 was inserted into the 1978 award, restricting "computer input" to members of the Printers Union. The clause indicated the union's "unswerving attitude that typesting [was] within the jurisdiction of the Printing Trades Union". The crucial sub-clause, $35: 5$, read:

2 Inferred from field data, and from writtien and oral submissions during the New Zealand Arbitration Court hearings - in Christchurch and Wellington, November 1981 - of the demarcation dispute between the printers and the clerical workers, referred to in the following section (see Hill, 1983).
Figure 2: Processing classified advertising under the CM11 system

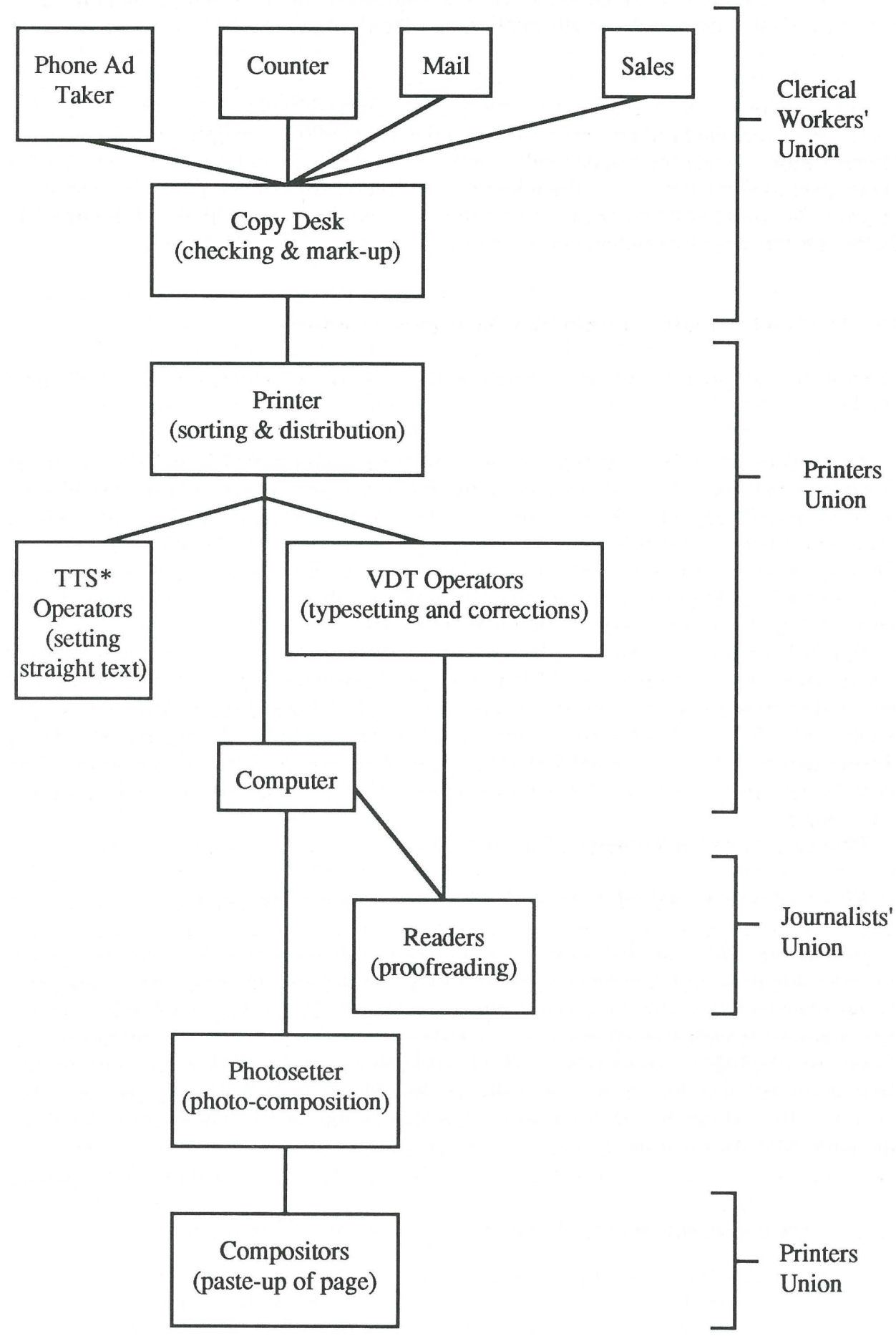

* Teletypesetter operators 
In offices equipped for computerised photo-setting, telephone operators receiving and processing copy for reproduction in the classified columns of a newspaper ... shall be members of the NZPTU. Such workers may be non-journeymen operators specified under... clause 17 of this agreement.

This attempt to gain collective control over the technology was not unanimously supported by Printers Union members, since it was in conflict with printing tradesmen's interests in retaining individual control at the workplace. The New Zealand Herald's chapel feared that Clause 35.5 might be used by employers as a wedge to further deskill the trade of typesetting and reduce the work of tradesmen, since computer formats could be written which embodied tradesmen's skills yet were capable of being activated by nonjourneymen members.

The chapel negotiated a separate house agreement with employers in breach of Clause 35:5 of the award. The special house agreement, negotiated in June, 1981, lapsed the following year when the Printers Union was successful in persuading the Herald chapel to abide by the terms of the award. Telephonist-typists at that newspaper office are now Printers Union members but are restricted to a limited range of typesetting work.

As has been argued, the union's collective interests were best served if control over typesetting and thus membership could be retained. Accordingly, the New Zealand Printers Union pursued a strategy to bring the telephonist-typists (who were clerical workers) into the union as 'non-journeymen' members. This strategy was facilitated by events which had occurred in 1954. In that year TTS or teletypesetter machines had been installed in New Zealand newspaper offices. These machines which had a qwerty keyboard similar to that of a typewriter, produced punched tape which was used to drive automatic line casting machines. The machines reduced the need for printing tradesmen and typographical skills, and threatened the men's subjective perceptions of themselves as skilled tradesmen. The men refused to operate the machines because "it wasn't work for skilled tradesmen ${ }^{3 "}$, and this allowed female non-journeymen keyboard operators into the Printers Union as TTS operators. ${ }^{4}$ In this new wave of technological change, printing tradesmen and union officials (in general) did not want another group of non-journeymen keyboard operators to join the union. In the words of a Christchurch Printers Union official, "it was TTS all over again". However, the threat of loss of control over the technology, and a drop in membership, was very real.

\section{Conflict between the Clerical Association and the Printers Union}

In January 1980, the NZ Clerical Employees' Association contested the Printers union's claim to coverage of the tele-ad operators. Throughout the protracted demarcation dispute which ensued, the Association contended that the tele-ad operation under the new computerised system remained clerical in nature. The Association refused to yield its traditional coverage of the clerical workers involved, although it was prepared to accept a division of membership on the basis of printing and clerical work respectively. The Printers Union continued to insist on exclusive coverage of the tele-ad work since the operation involved typesetting.

Conversation in a Wellington pub in November 1981, following sittings of the Court that day.

4 As Printing Union President, W. Clement, told the Arbitration Court in Christchurch in November 1981, "Female clerks, fast over the keyboard, were recruited to operate the machines because the tradesmen wouldn't belittle themselves or condescend to operate the TTS". At The New Zealand Herald I was told: "When the TTS machines first came in the guys wouldn't touch them: NOT machines for girls." The issue of gender and the development of the labour process is discussed fully in Hill, 1984a; Hill and Noritz,
de 1985; and Hill and Gidlow, 1988 .

Figure 3: Direct-inputting of telephone ads under the CMS system

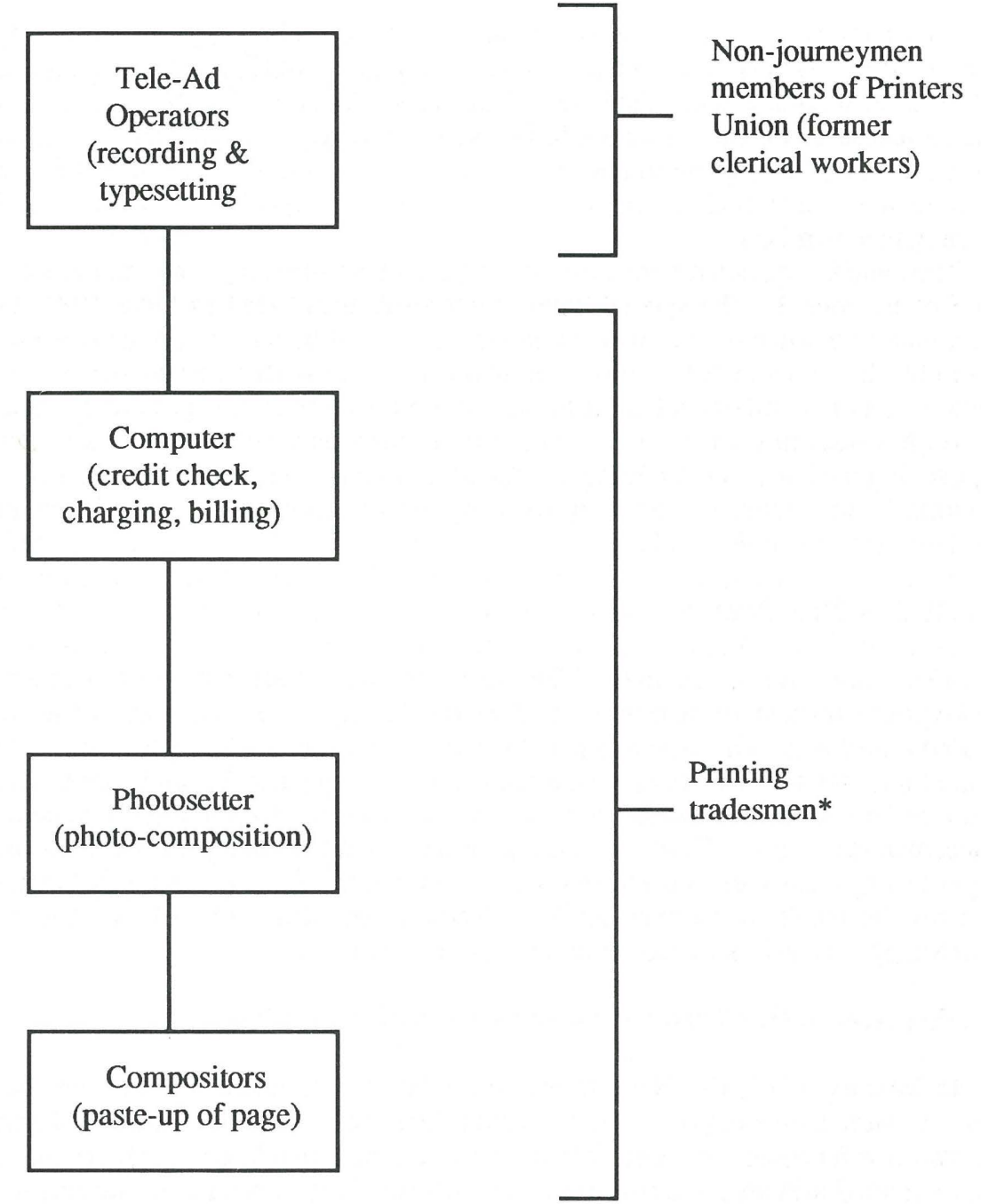

Note: No second keyboarding by VDT operators, no checking at copy desk and no separate proofreading.

(*In overall charge of the system.) 
The tele-ad operators themselves stood to gain a significant improvement in wages and working conditions from membership of the Printers Union. Therefore, objectively, their interests coincided with those of the Printers Union in its strategy over Clause 35:5. As a Canterbury Clerical Workers' Union official saw it,

Clerical workers haven't got loyalties to any union. They've got to belong to a union so they'd choose the one that'd pay the most. The carrot was waved before their nose and they took it. You can understand them. Their natural response would be 'what's in it for me?' The Printers Union was looking for heads. Their membership was dwindling.

In early 1980, 21 telephone operators at Wellington Newspapers Ltd resigned their membership of the Wellington Clerical Workers' Union and joined the Printers Union. Similarly, when the change to computerised typesetting was completed at The Press, 18 operators at that newspaper office resigned their membership of the Canterbury Clerical operators at that newspaper office resigned their membership of the Canterbury Clerical
Workers' Union on June 18,1981. Meanwhile, discussions between the two unions, and Workers' Union on June 18, 1981. Meanwhile, discussions between the two unions, and
with the employers, as well as mediation by the Federation of Labour (FOL), failed to produce a solution. On June 29, 1981, the Wellington Clerical Workers' Union applied to the Arbitration Court to settle the dispute. Four days earlier the Canterbury Clerical Workers' Union made an application to the Court to settle a similar demarcation dispute at The Press in Christchurch.

\section{The NPA and the Printers Union co-operate}

The Arbitration Court met in Christchurch and Wellington in November 1981, to resolve the respective demarcation disputes. During the hearings the NPA and the employers concerned backed the Printers Union's stand over the issue. The NPA's Executive Director, DJ. Patten, told the Court that his Association believed the work of the tele-ad operators must be covered by the Printers' Award since typesetting was a traditional function of Printers Union members, and tele-ad operators were involved in typesetting when they carried out their work on the VDTs. Similarly, employers at Wellington Newspapers and The Press argued that taking ads over the telephone, and entering the details and typesetting codes into a computer terminal, constituted printing and not clerical work. The Clerical Association and its constituent unions claimed that the computer terminal had merely replaced the typewriter, since - instead of manually controlling the typewriter for spacing under the old system - the worker now typed commands to the computer which provided the spacing and type-size. For this reason, commands to the computer which provided the spacing and type-size. For this reason,
they argued, the computer carried out the printing functions, not the workers. The they argued, the computer carried out the printing functions, not the workers. The
Printers Union responded: before setting the ad, the tele-ad operator had to visualise the Printers Union responded: before setting the ad, the tele-ad operator had to visualise the was printers' work.

Evidence was given in Court that the employers were anxious to avoid any industrial disruption which could ensue if the tele-ad operators did not join the Printers Union. Wellington Clerical Workers' Union Assistant Secretary, P.E. Tennet, for example, told the Court that in the early stages of the dispute the Printers Union:

threatened to refuse to accept work from the tele-ad operators thereby affecting the working of the newspaper so far as classified advertisements were concerned. At one stage it appeared as if a major industrial confrontation might ensue with a likelihood of stoppages in the newspaper industry.

Employers at Wellington Newspapers had, she said, "been anxious to avoid industrial disruption when it [had] been suggested by the Printers' Union". General Manager, W Kelso, conceded in cross-examination that the possibility certainly existed "that the
Printers Union would deal with the dispute by simply refusing to handle the work from the tele-ad operators". He pointed out, however, that although the union was very firm, "there were no threats" of industrial action.

On November 20, 1981, the Arbitration Court ruled in favour of the Printers Union.

\section{Job structure at The Star}

The organisation of the typesetting process and the associated job structure under The Star's new CMS System depended upon three related factors: (a) the events surrounding Clause 35:5, the Court hearing, and its outcome; (b) the variable nature of computer technology; and (c) relations of competition and co-operation at The Star, and between The Star and Christchurch's morning newspaper, The Press.

Clause 35.5 and the Court hearing

The Court ruling established that the telephonist-typists at The Star were legally members of the Printers Union. As a consequence, printing tradesmen in the composing room were prepared to handle the women's work, averting any disruption to production which might have eventuated if the Court had ruled in favour of the Clerical Workers' Union.

Acceptance by the printers enabled The Star's management to introduce the CMS system which eliminated the double handling of a large proportion of telephoned advertisements. At the same time, the system enabled management to streamline its billing and accounting procedures.

The Printers Union's successful strategy over Clause 35:5, ensuring that The Star's chapel retained control over the technology, meant that the printers could influence both the development of the CMS software and the training programme for the telephonisttypists (issues which are discussed in Hill and Gidlow 1988, Ch. 13). Moreover, the delay in the CMS system's implementation enabled the majority of the tradesmen in The Star's composing room to acquire typing and computer keyboard skills without direct competition from skilled typists also undergoing training on the terminals.

However, from the point of view of male printers at The Star, the outcome of the Arbitration Court hearing was a mixed blessing. The Court's ruling meant that for the first time at The Star female non-journeymen were able to use computer typesetting equipment formerly restricted to male tradesmen. The women's encroachment onto VDTs potentially reduced the amount of work available for printing tradesmen. Moreover, it posed a threat to their typesetting skills and - significantly - their status as skilled tradesmen since each occupational group now used the same technology, the same computer terminal, for type-setting. Only the software differed and this was not, of course, evident in a casual inspection of the work.

The Court hearing also threatened the men's subjective perceptions of their work on computer terminals. In order to establish the Printers Union's right to coverage of tele-ad operators' work, printers and employers and their legal representatives attempted to show both that printers' skills were fundamental to computerised typesetting of telephoned advertisements and that female clerical workers were able, or potentially able, to do the work of skilled tradesmen. For example, in response to a question by counsel for the employers, the production manager at The Press, L.R. Sullivan, told the Court that the women at The Press were setting "complicated weights and speed limits of vehicles. These are the skills of the printers ... and we now pass them on to the girls [sic]."

Defining the women's work as printers' work in this way entailed acknowledging that non-journeymen typists could do the work of skilled tradesmen. Present during the hearing in both Christchurch and Wellington were chapel, branch, and national Printers Union officials - all practising, or former, tradesmen. Details of the hearing and ruling 
were reported extensively in New Zealand newspapers, and these reports would have been typeset by printing tradesmen. Moreover, the Court ruling legally defined the women's work as that of a printer. Based on previous fieldwork experience and evidence from the Court proceedings it seems reasonable to conclude that the printers would resent hearing and reading their work defined in a way which they perceived as deskilling their trade.

\section{Computer technology: its variable nature}

In terms of an analysis of the job structure which emerged at The Star, it is important to appreciate that the outcome of the Court hearing determined only that tele-ad operators - as members of the Printers Union - would operate computer terminals. The area of discretion left to the individual tele-ad operator varied according to the extent to which typographical skills and knowledge were incorporated in the design of the system in the form of software, and this was not determined by the technology, but was the outcome of a process of in-house negotiation.

Put simply, at one extreme - with minimal programming - tele-ad operators would key in only the text of the advertisement as the customer relayed it to them over the telephone. All typesetting instructions would be entered in by tradesmen after the advertisement had been routed to them electronically. Only after this second handling of the advertisement would it be sent to the photosetter for photo-composition.

At the other extreme - with the system fully programmed - the run-on and space advertisements could all be typeset by tele-ad operators using 'formats'. As indicated earlier, a format was a shorthand way of instructing the computer to call up predetermined or programmed typesetting codes which automatically determine the position, shape, size and spacing of the text of the advertisement. Instead of visualising how the ad would appear and selecting typesetting codes for the individual words and lines of text, the operator would be limited to visualising which format best suited the entire text and then keying in the coding. Moreover, a formatted advertisement could be sent directly, by the tele-ad operator, to the photosetter for photocomposition.

\section{Relations of competition and cooperation}

Although the Printers' chapel at The Star collectively supported the union's stance over Clause 35.5, like the men in the Herald chapel, many of the tradesmen were unhappy with the implication - for job opportunity, skill and status - of the union's action and the Court ruling. The Star chapel therefore pursued strategies to retain the objective skill differences between the two jobs; that is, to resist the formatting made possible by Clause 35:5, and the Court's ruling. In doing so the chapel benefitted from management's concern that The Star retain a competitive edge over the morning newspaper, The Press, by offering customers a wide choice of advertising styles. Management and chapel negotiated an agreement that permitted the formatting of 23 of the more common typesetting styles and their use (under the new CMS system) in directinputting space ads originating over the telephone. This limited formatting meant that the men still set the more complex, single and double-column, space ads, and continued to be responsible for all tabulated material appearing in the paper. The printing task carried out by the newly-trained tele-ad operators were limited to setting straight run-on advertisements and using formats to set the simpler 'spaced' advertisements.

5 For example, in summarising the case for the Canterbury Clerical Workers' Union, counsel commented: "The weight of the printers' case is that it takes one month to bring a typist to the level of skills of what was the old-fashioned compositor." The antagonism of Printing Union officials seated behind me in the Court was quite marked.
The dilemma set by the struggle over clause 35:5, was not simply to prevent further objective deskilling - made possible by the technology and access to it by nonjourneymen operators - but also to resist the implied subjective deskilling. Thus, training for telephonist-typists at The Star involved not only learning typesetting skills and keyboard proficiency; it also involved a hidden curriculum by which the men in the composing room attempted to re-assert the status differential between their jobs and those of the former clerical workers. During training the printers in the composing room and of the former clerical workers. During training the printers in the composing room and training room was a partitioned section of the comp room.) They also had more frequen contact with chapel officials. Furthermore, during training, the tutor - a system controller and member of the chapel - explained the limited areas of typesetting knowledge accessible to the women. As one of the women put it:

The men make it seem like a secret society. You have to know the codes [to do the work required]. They don't want us to know

She spoke again about the issue later that day. "The men say all we'll do is the formats, just press one or two buttons. But we want to know it all."

\section{Conclusion}

The nature and timing of the changes occurring under the CMS system can be explained as the outcome of struggle, at both national and shop-floor level, for contro over the technology. Significantly, the struggle took place within the context of the flexible or programmable nature of computer technology. The New Zealand newspape employers wanted to utilise the full potential of this technology which allowed for single keyboarding of telephone advertisements. Organising work in this way secured more efficient, error-free production and cut wage costs. The Printers Union, at the centre of the struggle, fought to retain membership levels and its traditional control over typesetting. Thus, it accepted, in principle, single keyboarding of telephone ads and sought - successfully - to bring the telephonist-typists (who were clerical workers) into the Printers Union as non-journeymen members.

Once the dispute over union coverage of tele-ad operators was resolved at the national level, the question of how a classified management system would be designed at The Star and other newspapers was decided as a result of in-house negotiations among and between employers and different occupational groups - within the context set by negotiations over Clause 35.5. The Printers' chapel at The Star sought to defend the objective skills of its journeymen members by negotiating an agreement with management on the restricted use of computer formatting in the production of advertising copy.

However, the dilemma set The Star's chapel by the struggle over Clause 35.5 was not simply to prevent further objective deskilling but also to resist the subjective deskilling that was engendered by the struggle. Thus, retraining for telephonist-typists at The Star involved not only learning typesetting skills and keyboard proficiency; it also involved a hidden agenda by which the men in the composing room attempted to reassert the status differential between their jobs and those of the former clerical workers.

\section{References}

Elbaum, Bernard, et al. (1979) The labour process, market structure and Marxist theory Cambridge journal of economics 3:227-130. 
Hill, R (1983) From hot metal to cold type: labour process theory and new technology in the newspaper industry University of Canterbury, $\mathrm{PhD}$ thesis.

Hill, R (1984a) Gender, skill and technological change: the linotype operator and the VDT Women's studies: Conference Papers 1983 Auckland: Women's Studies Association.

Hill, R (1984b) From hot metal to cold type: new technology in the newspaper industry New Zealand journal of industrial relations 9(3):161-175.

Hill, R (1985) Field work as a female in a 'male' workplace: the process of gender at work Women's studies: Conference Papers 1983 Auckland: Women's Studies Association.

Hill, R and Gidlow, B (1988) From hot metal to cold type: negotiating technological change in the New Zealand newspaper industry Wellington: DSIR Publishing.

Hill, R and Novitz, R (1985) Class, gender and technological change Paper presented at NZSA Conference, University of Waikato.

Stark, David (1980) Class struggle and the transformation of the labor process Theory and society 9:98-130. 